\title{
Variação construcional por analogia: padrões construcionais de predicação verbal na voz passiva
}

\author{
Marcia dos Santos Machado Vieira ${ }^{1}$ \\ Júlia Lessa dos Santos ${ }^{2}$ \\ Morgana Pinheiro Albuquerque Kropf ${ }^{3}$
}

\begin{abstract}
Resumo: Este artigo versa sobre a temática do espaço da variação entre as generalizações da Gramática de Construções e sobre uma análise, sob olhar socioconstrucionista, de usos de padrões construcionais de predicação verbal na voz passiva. Objetiva apresentar argumentação em prol do estudo de variação linguística por similaridade e ilustrar variação de padrões construcionais de predicação verbal passiva (pronominal e analítica). Delineia-se com base em pressupostos da Linguística Funcional-Cognitiva, a qual se centra na experiência linguística. Em linhas gerais, colabora para a reflexão sobre a potencialidade de alinhamento funcional dos subesquemas construcionais e microconstruções independentes que chega a mapear, com base em metodologia de tratamento estatístico e em descrição de dados de sentenças na voz passiva sintética e analítica. Revela três possibilidades configuracionais de predicação verbal a partir do subesquema construcional de passiva pronominal e quatro possibilidades configuracionais de predicação verbal a partir do subesquema de passiva analítica.
\end{abstract}

Palavras-chave: Variação construcional; Predicação verbal; Passiva.

\section{Introdução}

Desde Machado Vieira $\left(2016^{4}\right)$, vem-se construindo uma argumentação em defesa de uma postura menos resistente, em Linguística Funcional-Cognitiva (LFC), à inclusão de variabilidade, alternâncias e variantes entre os conhecimentos do repertório linguístico e entre

1 Docente e pesquisadora do Programa de Pós-Graduação em Letras Vernáculas e do Departamento de Letras Vernáculas da Faculdade de Letras da UFRJ. Coordenadora do Projeto PREDICAR, membro do Grupo de Pesquisa Discurso \& Gramática da sede UFRJ, coordenadora do GT de Sociolinguística da ANPOLL, membro do Comitê de Ética em Pesquisa do IESC/UFRJ e de NDE de cursos de Graduação da Faculdade de Letras. Email: marcia@letras.ufrj.br.

2 Discente do Curso de Licenciatura em Letras: Português-Alemão da UFRJ, em Iniciação Científica no Projeto PREDICAR - Formação e expressão de predicados complexos. E-mail: julialessa@yahoo.com.

3 Discente do Curso de Letras: Português-Literaturas da UFRJ, em Iniciação Científica no Projeto PREDICAR Formação e expressão de predicados complexos. E-mail: morganakropf@gmail.com.

4 Tal artigo tem, na verdade, por base a defesa do lugar da variação na Gramática de Construções feita por ocasião da comunicação oral proferida durante o XXI Seminário Nacional do Grupo Discurso \& Gramática/VIII Seminário Internacional do Grupo D \& G, realizados na UFRJ de 4 a 7 de junho de 2016: variação e abordagem construcional. 


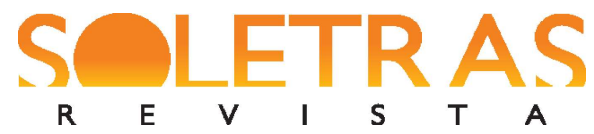

N.37 - 2019.1 - MARCIA DOS SANTOS MACHADO VIEIRA JÚLIA LESSA DOS SANTOS

MORGANA PINHEIRO ALBUQUERQUE KROPF

os objetos (observacional e teórico) que a arquitetura da gramática de construções não pode precindir de descrever, uma vez que se centra na experiência de usos social, contextual e cognitivamente situados, quer tais usos sejam rotineiros e centrais, quer sejam periféricos ${ }^{5}$. Essa argumentação fundamenta-se numa concepção de língua, como a que se vê materializada, entre outros textos de linguistas com orientação constucionista (HILPERT, 2014; CAPPELLE, 2006 e 2009), neste:

Language is a dynamic activity, so much so that if there is one thing that is 'constant and definitional of language, it is constant change. And in order for change to take place, there has to be (at least a potential for) variation, which we consider to be a linguistic manifestation of variability (as a general human resource).

Issues of variation and variability have been only indirectly addressed within CxG. (...) Our view is that variability is just as central to the undertanding of how linguistic units behave in grammar, as is stringency in terms of constructions.

If we want to take seriously the aim of $C x G$ to deal with all constructs of a language, be they 'core' members or 'peripheral' constructs, we cannot brush variation aside. (...)

Language change, variation, language acquisition and language learning involve adaptability ${ }^{6}$ (LEINO \& ÖSTMAN, 2005, p. 192).

Trata-se aqui, especificamente, de variação linguística (ou "alternância") baseada em relação de similaridade de variantes desencadeada por analogia, um processo de associação de propriedades dos atributos envolvidos nas faces forma-função de certos pareamentos, na

5 "a full-fledged grammatical description of a language should be able to capture not only 'core' phenomena, but also sporadic, 'peripheral' phenomena." (LEINO \& ÖSTMAN, 2005, p. 209) / "uma descrição gramatical completa de uma língua deve ser capaz de capturar não apenas fenômenos "centrais", mas também fenômenos esporádicos e "periféricos".

6 A linguagem é uma atividade dinâmica, tanto que, se há uma coisa que é "constante" e caracterizadora da linguagem, é mudança constante. E para que a mudança ocorra, tem de haver (pelo menos um potencial para) variação, o que consideramos ser uma manifestação linguística de variabilidade (como um recurso humano geral). Questões de variação e variabilidade foram abordadas apenas indiretamente na GC (Gramática de Construções). (...) Nossa visão é a de que a variabilidade é tão central para o entendimento de como as unidades linguísticas se comportam na gramática, quanto o rigor/a regularidade ou estabilidade em termos de construções. Se quisermos levar a sério o objetivo da GC de lidar com todos os constructos de uma linguagem, sejam eles "membros centrais" ou construções "periféricas", não podemos afastar a variação. (...) Mudança linguística, variação, aquisição de linguagem e aprendizagem de idiomas envolvem adaptabilidade. 


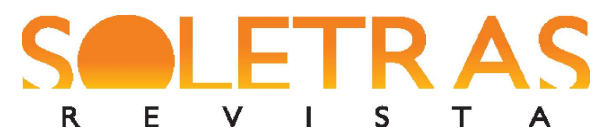

N.37 - 2019.1 - MARCIA DOS SANTOS MACHADO VIEIRA JÚLIA LESSA DOS SANTOS

MORGANA PINHEIRO ALBUQUERQUE KROPF

gramática do Português. Pretende-se explorar, a título de ilustração ${ }^{7}$, associações de padrões construcionais relacionados à conceptualização de eventos/estados de coisas e, em certa medida, sob uma perspectiva de desfocalização discursiva de participante $^{8}$.

Este artigo situa-se, então, numa perspectiva funcional-cognitiva centrada na experiência linguística e voltada para o mapeamento de generalizações da Gramática de Construções do Português, lida com um fenômeno (a variação) que pode ensejar mudança linguística, bem como com a concepção de alinhamento entre certas propriedades envolvidas nas dimensões com base nas quais pareamentos forma-função se convencionalizam (na sua face formal, atributos prosódicos, fonético-fonológicos, morfológicos, sintáticos; na sua face funcional, atributos semânticos, discursivos, pragmáticos, sociais e cognitivos ${ }^{9}$ ).

Procurou-se organizá-lo em duas seções. Na primeira parte, no intuito de fazer emergirem generalizações sobre variação na Gramática Construcional, tecem-se observações sobre estas questões:

(1) Em que medida a proposta de debate sobre o lugar da variação na modelagem construcionista concorre para o refinamento de pressupostos da Linguística Funcional Centrada no Uso (LFCU)?

(2) Quais são os problemas, de ordem teórica e/ou conceitual, que se apresentam ao abordar esse tema?

(3) Como, em termos teórico-metodológicos, esses problemas interferem nos resultados de análise?

7 Resultados aqui expostos advêm de pesquisas em andamento no Projeto PREDICAR - Formação e expressão de predicados complexos: estabilidade, variação e mudança construcional.

8 A desfocalização discursiva é uma estratégia de polidez ou preservação da face (BROWN \& LEVINSON, 1987) comum no discurso acadêmico.

9 Tais atributos, por sua vez, desdobram-se, no processo de análise, em subgrupos de fatores/atributos que assumem diferentes valores, inclusive em termos de preempção estatística, em um sistema de associação de construções (independentes) em alternância. "Statistical preemption assumes that formulations that are witnessed compete with other formulations that might be expected to occur in a given context." (BOYD \& GOLDBERG, 2011, p. 59) / "A preempção estatística pressupõe que as formulações que são testemunhadas competem com outras formulações que podem ocorrer em um determinado contexto”. 


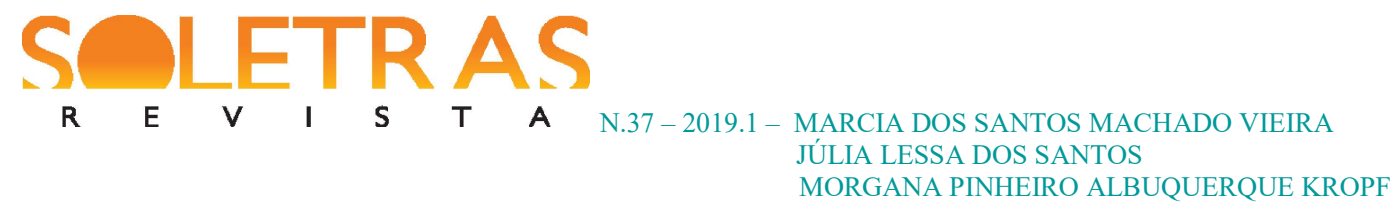

(4) Que possibilidades de ordem teórico-metodológica minimizariam ou até sanariam os problemas? E, então, de que forma a metodologia de pesquisa pode ser ajustada para dar conta de proposição teórico-metodológica aqui esboçada?

$\mathrm{Na}$ segunda parte, ilustra-se uma possibilidade de estudo, sob viés socioconstrucionista, para captar, na Gramática de Construções do Português, a potencialidade de generalização sobre variação e formas alternantes de predicação verbal na voz passiva, aqui baseada na análise de usos presentes no universo acadêmico. A possibilidade de exame de dados aqui contemplada se assemelha ao exame de variação entre os padrões construcionais ditransitivo e dativo preposicional delineado em Hilpert (2014: cap. 8). Também tem ligação com o exame sobre fatores que influenciam probabilisticamente a alternância de estruturas ativas e estruturas passivas na escrita acadêmica em diferentes variedades do Inglês em Hundt, Röthlisberger \& Seone (2018).

\section{Em discussão: a potencialidade de variação linguística na arquitetura da LFC.}

\section{Contribuição para o refinamento de pressupostos}

O direcionamento da pesquisa em LFC com inclinação construcional e centrada no uso tem normalmente dois sentidos: ou se volta ao que é estável porque se mantém regular ou ao que é instável porque muda/está em processo de mudança. Neste caso, existe, em potencial, o fenômeno de variação de que, muitas vezes, sequer se cogita como objeto observacional, já que tal caráter instável se desenha exclusivamente com base no fenômeno de mudança ou, quando muito no fenômeno de variação por polissemia (voltando-se, ainda, para mudança).

Em tal direcionamento, muitas vezes parece haver uma certa idealização de língua e de falante/comunidade de fala. Afinal, se a gramática emerge da experiência de uso e indivíduos/comunidades estão sujeito(a)s a inputs diferentes a depender do fator contextualidade $^{10}$, a previsão ou não de instabilidade como variação (não só por competição

10 Contextualidade é um parâmetro envolvido no processo de ajustamento (afinação) da significação de formas linguísticas que o processo de interpretação de expressão linguística (ou não) implica. Com base em Goldberg (2016), entre outros estudiosos, tal parâmetro pode abarcar e/ou relacionar: (i) aspectos de conhecimento de 


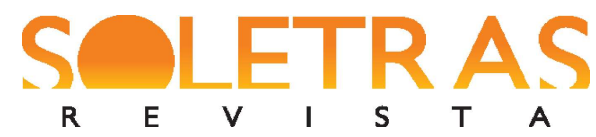

N.37 - 2019.1 - MARCIA DOS SANTOS MACHADO VIEIRA JÚLIA LESSA DOS SANTOS

MORGANA PINHEIRO ALBUQUERQUE KROPF

mas também por convivência) pode ter implicação em como se operacionaliza a representação dessa complexa relação na rede de construções e constructos.

De modo a alcançar adequação observacional, descritiva e explicativa, um modelo centrado no uso não pode perder de vista, em suas generalizações e formalizações, a necessidade de acomodar qualquer possibilidade de manifestação/realização do conhecimento linguístico estocado na memória. Se se detectam relações de similaridade entre unidades linguísticas convencionalizadas, estas têm de estar entre as generalizações. Perek (2015, 2012), com base em pesquisa experimental, soma evidência empírica à defesa de integração das "alternâncias" no modelo da Gramática das Construções.

\section{Desafios de ordem teórica e/ou conceitual}

Reestruturação/ajuste em concepções teórico-metodológicas e no formalismo de pesquisa com orientação construcional em LFC impõe-se para que este modelo dê conta adequadamente de casos de variação (ainda que raros ou periféricos) detectados na experiência do uso e, assim, se amplie o alcance explanatório de seu conjunto de generalizações e se fortaleça o caráter preditivo destas.

Um ajuste, por exemplo, diz respeito à postura (diga-se de passagem, mais tolerante em relação ao lugar do fenômeno de variação na LFC) de vislumbrar apenas a possibilidade de "competição de variantes". Afinal, dados dos usos (cf. MACHADO VIEIRA, 2016) sinalizam a potencialidade de convivência estável entre variantes (sem indício de um processo de mudança em curso). E mesmo registros em testes de avaliação subjetiva têm deixado

mundo, (ii) aspectos da enunciação, de seus componentes ou do suporte desta, (iii) aspectos de conhecimento pragmático, discursivo ou textual (relativamente) estabilizados ou da relação destes com inferências e aspectos do enunciado (como situação de ênfase ou contraste ressaltada mediante configuração sentencial com uma ou outra entonação), (iv) aspectos de referencialidade (dêitica ou não) e até de elipse. Entende-se, a partir de Goldberg (2016), que: (a) "Information beyond the immediate constituent is used in order to arrive at the meanings of words, and there are not always any linguistic cues about the required interpretation." / "Informações além do constituinte imediato são usadas para se chegar ao significado das palavras, e nem sempre há pistas linguísticas sobre a interpretação requerida." e (b) "As Gilles Fauconnier has described it, if the interpretation of a sentence is an iceberg, the sentence itself provides only the above-the-water-line peaks of the iceberg. People supply the rest of the meaning on the basis of shared context and world-knowledge." / "Como Gilles Fauconnier descreveu, se a interpretação de uma frase é um iceberg, a sentença em si fornece apenas os picos acima do nível da linha de água do iceberg. As pessoas fornecem o resto do significado com base no contexto compartilhado e no conhecimento do mundo". 


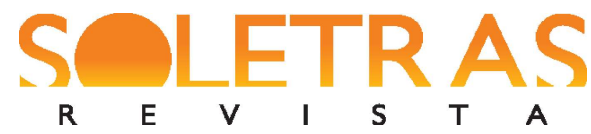

N.37 - 2019.1 - MARCIA DOS SANTOS MACHADO VIEIRA JÚLIA LESSA DOS SANTOS

MORGANA PINHEIRO ALBUQUERQUE KROPF

entrever um conhecimento do falante nesse sentido (no sentido de que há, à sua disposição em algumas construções em relação de comparabilidade, formas alternantes). Verificaram-se indícios de convivência de variantes, por exemplo, em estudo sobre a flexão de número em locuções verbais (a) com os modais poder e deixar que operam sobre verbos predicadores transitivos diretos seguidos de sintagmas nominais com núcleo nominal flexionado no plural e (b) em construções com SE apassivador/indeterminador (SILVA, FONTENLOS \& JUSTEN, 2017) ${ }^{11}$. Os índices de distribuição dos dados por flexão do modal (singular e plural) em textos do domínio acadêmico-científico ficam geralmente próximos ao ponto neutro $(50 \%)$, até quando se investe num olhar de diferenças/nuanças (por análise de condicionamentos). Índices similares (também relativos a locuções com tais modais) foram detectados noutra pesquisa de amostra diferente (inclusive, com locuções com outras configurações - com (semi)auxiliares temporais, aspectuais) ${ }^{12}$.

Supõe-se que a formulação "competição de variantes" seja considerada haja vista, talvez, a conjectura de uma espécie de luta entre padrões construcionais gramaticais de uma língua por centralidade (ou até "totalitarismo") no licenciamento de constructos. De todo modo, tal formulação também advém, em certa medida, de uma postura científica que se volta para a mudança e, então, pode terminar por mitigar o lugar da variação.

\section{Implicações teórico-metodológicas desses desafios nas análises}

As faces - forma e função - de uma construção precisam ser multidimensionalmente examinadas e descritas. Afinal, entende-se que forma engloba aspectos prosódicos, fonéticofonológicos, morfossintáticos, lexicais e que significado/função envolve atributos semânticos, discursivos, pragmáticos, sociais e cognitivos. A priorização de qualquer desses atributos não fará jus ao que se apresenta em língua. Muitas vezes, no entanto, a representação que se faz do pareamento é parcial no sentido de que frequentemente se limita a aspectos morfossintáticos e semânticos. E uma consequência que tal postura metodológica enseja é a

11 SILVA, FONTENLOS \& JUSTEN (2017) Que tendências se pode(m) encontrar em textos escritos brasileiros? Comunicação apresentada durante a 39 $9^{\mathrm{a}}$ Jornada Giulio Massarani de Iniciação Científica, Tecnológica, Artística e Cultural da UFRJ. Pesquisa desenvolvida no âmbito do Projeto PREDICAR.

12 Cf. MACHADO VIEIRA (2015). 


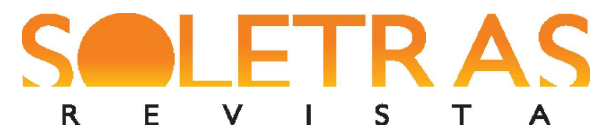

N.37 - 2019.1 - MARCIA DOS SANTOS MACHADO VIEIRA JÚLIA LESSA DOS SANTOS

MORGANA PINHEIRO ALBUQUERQUE KROPF

de alguém conjecturar que tolerar variação em LFC significará desconstruir uma relação pareada forma-significado/um pareamento, uma vez que duas ou mais formas teriam o mesmo significado, seriam idênticas. E, assim, haveria apenas um padrão construcional a dar conta da compatibilização das diferentes formas e, então, a licenciar constructos.

Também é necessário encarar devidamente o princípio de não-sinonímia (GOLDBERG, 1995), com base no qual (nos corolários A e B) tal pesquisadora faz alusão à possibilidade de sinonímia ou semântica ou pragmática e descarta a possibilidade de sinonímia em todas as dimensões da face funcional (atributos funcionais).

Outra implicação diz respeito à concepção idealizada ou não de língua/variedade de língua com base numa concepção de comunidade de fala também idealizada ou não. Num modelo que se intitula "centrado no uso", é problemático ignorar ou obliterar que a rede de construções pode (re)configurar-se a depender de amostras diferentes de constructos (no que diz respeito a propriedades do parâmetro da contextualidade).

\section{Possibilidades e ajustes de ordem teórico-metodológica à vista}

Pode-se conceber a variação com base em relação de similaridade (por comparabilidade, alinhamento, sinonímia "imperfeita"), que é traçada pelos falantes e/ou é ensejada por conta de links de herança/instanciação ${ }^{13}$. E pode-se cogitar de, pelo menos, duas possibilidades de unidades simbólicas submetidas a esse tipo de relação: (1) padrões construcionais e (2) unidades que se compatibilizam em slots de padrões construcionais mais ou menos esquemáticos.

13 Links de herança (TROUGOTT \& TROUSDALE, 2013, p. 61): links taxonômicos que capturam um tipo de relação entre construções ( sua organização em diferentes níveis de categorização de sua generalidade - abstração e esquematicidade - como esquemas, subesquemas, microconstruções e, em algumas representações da rede, ainda types construcionais). Cada construção corresponde a um nó na rede construcional/gramática com seus "taxonomic constraints"/ suas restrições ou motivações taxonômicas. Links de intanciação ou de instância (TROUGOTT \& TROUSDALE, 2013, p. 60): links relacionais que capturam construções particulares (inclusive “casos especiais") a partir de sanção (total ou parcial, esta especialmente nos "casos especiais") advinda de uma construção mais esquemática ou até de mais de uma construção simultaneamente. A título de ilustração, entendese que "O astronauta foi pro espaço", bem como "Minha avó foi pro céu" são instâncias da construção de movimento causado, por que dela herdam atributos. Só que a segunda também é instância metafórica de construção de predicação com verbo suporte; esta, por sua vez, mantém, no Português, relação de alternância por similaridade com o lexema "morreu". 


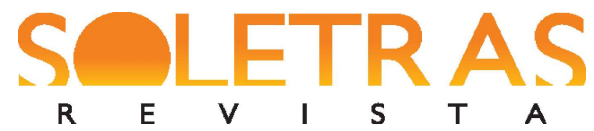

N.37 - 2019.1 - MARCIA DOS SANTOS MACHADO VIEIRA JÚLIA LESSA DOS SANTOS

MORGANA PINHEIRO ALBUQUERQUE KROPF

Não se trata de conceber identidade entre padrões construcionais ou entre formas que se compatibilizem no preenchimento do slot de um padrão construcional ${ }^{14}$, mas de considerar a potencialidade de variação em razão de um certo alinhamento entre propriedades de atributos de pareamentos independentes ou entre propriedades dos elementos linguísticos que se compatibilizam num padrão construcional. Nem mesmo em Sociolinguística se têm encarado variantes como idênticas, quer seja em decorrência de um dos problemas de investigação na agenda desse modelo (associação das variantes a condicionamentos, de natureza diversa), quer seja em virtude de práticas de investigação científica (cf. ECKERT, 2012) que podem ajudar a desfazer essa ideia (construída na esteira de outras práticas de pesquisa, principalmente da primeira onda da Sociolinguística, que se desenharam a partir de um conceito limitado de mesmo valor de verdade (como identidade) ${ }^{15}$ e da associação desse conceito a elementos do plano fonético-fonológico da língua), quer seja em razão da importância que o valor social/estilístico ${ }^{16}$ (e também contextual e cognitivo) da variação tem para esse modelo.

14 Por exemplo, no slot de verbos (semi)auxiliares em construções perifrásticas aspectuais de fase inicial (PEREIRA, 2016).

15 Vale lembrar, por exemplo, de estudos de Labov (1972), sobre a variação de predicações na voz ativa e na voz passiva (variantes sintáticas não idênticas) e sobre a centralização dos ditongos /ay/ e /aw/ em Martha's Vineyard (preocupação com a construção da persona).

16 "The first wave of variation studies established broad correlations between linguistic variables and the macrosociological categories of socioeconomic class, sex, ethnicity, and age. The second wave employed ethnographic methods to explore the local categories and configurations that inhabit, or constitute, the broader categories. In both waves, variation was seen as marking social categories." (ECKERT, 2012: 87) "Whereas the first two waves viewed the meaning of variation as incidental fallout from social space, the third wave views it as an essential feature of language. Variation constitutes a social semiotic system capable of expressing the full range of a community's social concerns. And as these concerns continually change, variables cannot be consensual markers of fixed meanings; on the contrary, their central property must be indexical mutability. This mutability is achieved in stylistic practice, as speakers make social-semiotic moves, reinterpreting variables and combining and recombining them in a continual process of bricolage (HEBDIGE, 1984)." (ECKERT, 2012, p. 94) / "A primeira onda de estudos de variação estabeleceu amplas correlações entre as variáveis linguísticas e as categorias macrossociológicas da classe socioeconômica, sexo, etnia e idade. A segunda onda empregou métodos etnográficos para explorar as categorias e configurações locais que integram, ou constituem, as categorias mais amplas. Em ambas as ondas, a variação foi vista como marcação de categorias sociais.”

Enquanto as duas primeiras ondas viam o significado da variação como uma conseqüência acidental do espaço social, a terceira onda a vê como uma característica essencial da linguagem. A variação constitui um sistema semiótico social capaz de expressar toda a gama de preocupações sociais de uma comunidade. E como essas preocupações mudam continuamente, as variáveis não podem ser marcadores consensuais de significados fixos; pelo contrário, sua propriedade central deve ser mutabilidade indexical. Essa mutabilidade é alcançada na prática estilística, à medida que os falantes fazem movimentos sócio-semióticos, reinterpretando variáveis e combinando-os e recombinando-os em um processo contínuo de bricolagem (HEBDIGE, 1984)." 


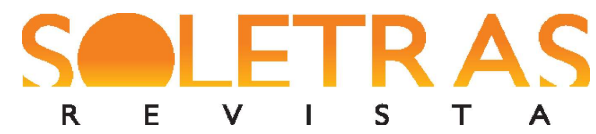

Em relação especificamente ao alinhamento/à comparabilidade entre padrões construcionais, pode-se cogitar de conceitos teóricos como allostructions (aloconstruções, à semelhança da base conceitual de alofones e alomorfes) e "supercategoria"/"metaconstrução" (uma espécie de área de abrangência das relações de associação de padrões construcionais, de significação comum a padrões construcionais independentes) na modelagem da LFC.

Para rotular as "variantes" envolvidas no processo de associação de propriedades de atributos de padrões construcionais independentes, Cappelle (2006 e 2009) e Leino \& Östman (2005) sugerem o conceito de allostructions (aloconstruções): "variant structural realizations of a construction that is left partially under specified" (CAPPELLE, 2006: 18). E, entre as observações que tece, o autor ainda diz: "The two allostructions are not in complementary distribution. That is, in many discourse environments, they may substitute for one another without bringing about a change in (truth-conditional) meaning." ${ }^{17}$ (CAPPELLE, 2006, p. 19).

Para capturar a área comum a variantes construcionais, Cappelle (2006) considera a possibilidade de uma supercategoria em que tais variantes se interconectem. Leino \& Östman (2005), ao mencionarem a marcação de caso no sujeito na língua finlandesa, sugerem o conceito de metaconstrução (como generalização sobre padrões construcionais independentes em relação analógica sistemática ${ }^{18}$, assim como a construção é uma generalização sobre constructos; como generalização pautada numa área de valores dos atributos):

Finnish subject case marking involves a kind of variability where certain expressions need to make reference to analogy: several clearly existing constructions are used as models in such a way that none of them by itself licenses the resulting expression. This kind of variation cannot be handled by reference to 'competing constructions ${ }^{19}$ (p. 204)

\footnotetext{
17 "Realizações estruturais variantes de uma construção deixada parcialmente subespecificada" (CAPPELLE, 2006, p. 18). “As duas alocuções não estão em distribuição complementar. Ou seja, em muitos ambientes discursivos, elas podem substituir uma a outra sem provocar uma mudança no significado (valor de verdade)."

${ }^{18}$ [Metaconstructions] "they capture systematic similarities and differences which occur between several pairs of constructions". (p. 207)

${ }^{19}$ A marcação de caso sujeito no finlandês envolve um tipo de variabilidade em que certas expressões precisam fazer referência à analogia: várias construções claramente existentes são usadas como modelos de tal forma que nenhuma delas por si só licencia a expressão resultante. Esse tipo de variação não pode ser tratado por referência a "construções concorrentes".
} 


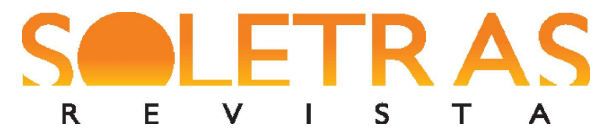

N.37 - 2019.1 - MARCIA DOS SANTOS MACHADO VIEIRA JÚLIA LESSA DOS SANTOS

MORGANA PINHEIRO ALBUQUERQUE KROPF

\section{Em análise: variação, por similaridade, na predicação verbal na voz passiva}

Da pesquisa sobre variação na estruturação de predicações verbais quanto à categoria voz em variedades do Português no Projeto PREDICAR ${ }^{20}$, trata-se, nesta ocasião, de variantes em jogo na voz passiva, de valores de seus atributos que, na comparação entre elas, são delineados como similares, bem como de valores de seus atributos que se configuram como diferentes. E, antes de se iniciar tal descrição sob um viés socioconstrucionista ${ }^{21}$, tecem-se considerações sobre a relação entre predicação verbal e contextualização de papéis sociais nesse processo e apresentam-se brevemente aspectos de ordem metodológica.

\section{Predicação verbal passiva e a contextualização do participante indutor de estados de coisas (papel participante 1)}

Um pressuposto no estudo é o de que enunciadores envolvidos no processo de processamento/representação de significado mediante linguagem (verbal ou não-verbal) num espaço de interação sociocomunicativa agem de modo a revelar seu ponto de vista. E uma maneira de revelar ponto de vista relaciona-se à configuração linguística mediada por predicação verbal. Diferenças na configuração linguística de predicações verbais propiciam a enunciadores acessar à perspectivação de papéis participantes envolvidos no estado de coisas a processar/representar.

Interfere, nessa atividade linguística, o parâmetro de contextualidade. Contextualidade é, em linhas gerais, uma operação dinâmica e, por conseguinte, provisória de enquadramento das atividades linguísticas. Tal enquadramento se define no espaço de interação/comunicação com base: em ações cognitivas - na (des)focalização de elementos indiciais da interpretação, por exemplo -; no entorno sócio-histórico-cultural representado na memória (mediante

\footnotetext{
${ }^{20}$ KROPF, M. P. A. \& SANTOS, J. L. dos S. (2018) Comunicação apresentada durante a $9^{\text {a }}$ Semana de Integração Acadêmica da UFRJ, 40 Jornada Giulio Massarani de Iniciação Científica, Tecnológica, Artística e Cultural da UFRJ. Pesquisa desenvolvida no âmbito do Projeto PREDICAR.

${ }^{21} \mathrm{O}$ olhar até então adotado vem sendo construído a partir da compatibilização de pressupostos da Gramática de Construções e da Sociolinguística. Assim sendo, tem, em certa medida, por inspiração o caminho trilhado no Sociofuncionalismo (TAVARES \& GORSKI, 2015).
} 


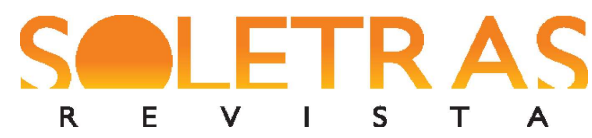

N.37 - 2019.1 - MARCIA DOS SANTOS MACHADO VIEIRA JÚLIA LESSA DOS SANTOS

MORGANA PINHEIRO ALBUQUERQUE KROPF

modelos cognitivos); em conhecimentos hitórico-sócio-culturais e discursivo-pragmáticos que emergem na situação comunicativa; em expectativas sobre o interlocutor, o conhecimento pragmático deste e a interação discursiva num certo domínio comunicativo. E as pistas de interpretação são fornecidas, por, entre outros meios (verbais e não-verbais), recurso a determinados padrões construcionais de predicação de uma língua.

No repertório da língua portuguesa, há estratégias para a contextualização de papéis participantes ligados a predicadores verbais em construções de estrutura argumental transitiva (que impliquem, no mínimo, dois argumentos representados por sintagmas nominais), tais como: a (des)focalização/(des)focamento ${ }^{22}$ de um papel participante/objeto de discurso e/ou sua (des)ativação. No primeiro processo, ou ocorre encobrimento de um papel participante na perspectivação (cf. exemplos 1, 2, 3 e 4), ou há sua explicitação focal pelo processo de focalização (cf. exemplo 5 adiante). No segundo processo, pode haver ou não ativação/apresentação em primeiro plano, na predicação, do papel participante correspondente àquele que induz (realiza, porta ou experimenta) o estado de coisas (ou não, em caso de polaridade negativa). Não havendo ativação/perspectivação desse papel participante, outras alternativas de predicação verbal podem-se configurar: demoção/eversão do papel participante indutor para o papel argumental de complemento verbal (cf. exemplo 4), com a perspectivação/ativação do papel participante 2, correspondente ao que é afetado ou efetuado pelo estado de coisas, é experimentado ou beneficiado no estado de coisas; a circunstancialização desse papel participante 1, que se dá quando o papel participante indutor é realizado linguisticamente por meio de adjuntos circunstanciais (introduzidos por formas adverbiais ou preposicionais, em alguns casos iniciados por "por/pelo/pela" ou "de", que aparentem ser origem/força indutora ${ }^{23}$ ), conforme se verá adiante (cf., também, exemplos 10 e 13).

22 O termo desfocamento de agente foi proposto por Shibatani (1985, p. 832) como uma função discursivopragmática primária e não como uma mera consequência da promoção do objeto/paciente.

23 Ex.: "Tal procedimento FOI logo LEVADO a efeito no início do século, por iniciativa do corregedor da comarca, que enviou um regimento à cidade, onde, entre outras coisas, ordenava a remoção de esterqueiras no espaço urbano, ciente do seu impacto negativo para a saúde pública. [Revista da Faculdade de Letras. História Série III, vol. 5, 2004 pg. 164] 


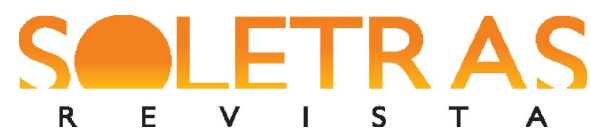

N.37 - 2019.1 - MARCIA DOS SANTOS MACHADO VIEIRA JÚLIA LESSA DOS SANTOS

MORGANA PINHEIRO ALBUQUERQUE KROPF

Ex. 1: As diversas tentativas de SE CRIAR uma universidade no Brasil colonial, foram negadas pela Coroa, sucessivas vezes. [Revista da Faculdade de Letras, História, Série IV, Vol. 07, Num. 2, 2017pg. 55]

Ex. 2: Em todas as betonagens OBTIVERAM-SE valores relativamente próximos, à exceção da B2, sendo que o valor médio da resistência à compressão do betão foi de $52.7 \mathrm{MPa}$. [Revista de Engenharia Civil , 2015, No. 51, 5-22A; p. 8]

Ex. 3: "A análise das elites aconselha, também, que SEJAM OBSERVADAS as várias razões que podem determinar a fragilização e até o desaparecimento de uma elite." [Revista da Faculdade de Letras, História, Série IV, Vol. 07, Num. 2, 2017 p. 6]

Ex.4: "O facto de a Vereação não poder suprir tal despesa levou a que se sugerisse que este corpo médico FOSSE PAGO por um rol de beneméritos da cidade, que a apoiariam nesta iniciativa." [Revista da Faculdade de Letras, História, Série III, vol. 5, 2004 p. 163]

Ex. 5: "Cada língua, dentro do conjunto das línguas sujeitas à CM, DEFINIRÁ assim a quantidade mínima de material fonológico obrigatoriamente contido por uma palavra [MCCARTHY \& PRINCE 1995].” [Revista de Estudos Linguísticos da Universidade do Porto, Vol. 12, 2017, pg. 205]

No conjunto de padrões construcionais (subesquemas construcionais e microconstruções) da construção/esquema construcional de predicação verbal, conta-se com padrões de predicação passiva, com base nos quais se pode perspectivar o papel participante indutor (agente, experienciador, dizente, portador) com encobrimento total ou com encobrimento parcial. Na primeira possibilidade de ação, ele nem é materializado, ficando suspenso. Na segunda, ele é posto em segundo plano.

A supressão de papel participante indutor de estado de coisas numa predicação verbal é basicamente realizada, em Português, mediante a organização de sentença na voz passiva sintética/pronominal. E também pode ser obtida pela organização de sentença na voz passiva analítica, desde que nesta não se materialize tal participante. $\mathrm{O}$ encobrimento parcial do papel participante indutor pode ser alcançado mediante sua materialização como complemento verbal "agente da passiva"/oblíquo que, inclusive, pode ser preenchido por expressões 


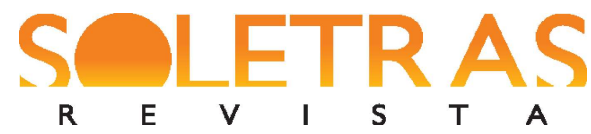

N.37 - 2019.1 - MARCIA DOS SANTOS MACHADO VIEIRA
JÚLIA LESSA DOS SANTOS
MORGANA PINHEIRO ALBUQUERQUE KROPF

nominais ou pronominais genéricas e/ou plurais que não levem o interlocutor a acessar um referente específico no mundo discursivo ou biossocial, pelo menos não diretamente (haja vista o fato de que a circunstancialização pode propiciar acesso/referencialidade indireto(a) ao papel participante indutor).

No corpus em análise, é expressivo o número de constructos/usos relacionados a dois subesquemas construcionais de predicação na voz passiva (passiva sintética/pronominal e passiva analítica) e sete possibilidades configuracionais desse tipo de predicação verbal ligadas a microconstruções que herdam propriedades daqueles subesquemas. Em parte significativa do corpus, constructos de tais subesquemas materializam a potencialidade que estes têm de se alinharem funcionalmente, em decorrência de analogia, particularmente no que diz respeito à propriedade que revelam quanto à desfocalização do referente-indutor previsto num estado de coisas. Sintetiza-se, a seguir, o mapeamento de tais padrões construcionais, começando-se, a título de ilustração, pelo que estrutura sentenças na voz ativa, com focalização de referente-indutor:

(i) constructo/uso de padrão construcional na voz ativa com focalização de referenteparticipante indutor

Ex. 6: "A análise das elites ACONSELHA, também, que sejam observadas as várias razões que podem determinar a fragilização e até o desaparecimento de uma elite." [Revista da Faculdade de Letras, História, Série IV, Vol. 07, Num. 2, 2017 p. 6]

(ii) constructos/usos de padrão construcional na voz passiva sintética com encobrimento total de referente-participante indutor, com sua suspensão (supressão default)

Ex. 7:“Em 1950 existiam cerca de 5000 grandes barragens (com altura superior a 15 metros), sendo actualmente o seu número de cerca de 45000, o que significa que nestes 50 anos $\mathbf{S E}$ CONSTRUÍRAM, em média, 2 grandes barragens por dia." [Revista de Engenharia Civil, 2003, No. 16, 5-12 I; p. 5]

Ex. 8: PROCURAM-SE novas soluções que permitam a viabilização da construção em terra no contexto atual e que alterem o preconceito gerado em torno do material. [Revista de Engenharia Civil, 2013, No. 46, 5-17 I; p. 28] 


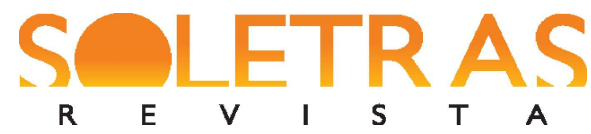

N.37 - 2019.1 - MARCIA DOS SANTOS MACHADO VIEIRA
JÚLIA LESSA DOS SANTOS
MORGANA PINHEIRO ALBUQUERQUE KROPF

(iii) constructo/uso de padrão construcional na voz passiva sintética com encobrimento parcial de referente-participante indutor (pesquisador/autor do texto acadêmico)

Ex. 9: Para tal, foram selecionadas fibras têxteis, acrílicas, de vidro, de basalto, de banana e de sisal e ESTUDOU-SE o efeito da sua incorporação em composições diferentes à base de gesso, procurando avaliar o seu comportamento, quer no estado fresco, quer no endurecido. [Revista de Engenharia Civil 2013, No. 46, 5-17 I, p. 5]

(iv) constructo/uso de padrão construcional na voz passiva sintética com encobrimento parcial de referente-participante indutor (circunstancializado)

Ex. 10: Em o Eco Farmacêutico, NOTICIA-SE em toda a primeira página: "Morreu Fleming!". Trata-se de um artigo que traduz de modo exemplar a mitificação da figura e da personalidade de Fleming.

(v) constructo/uso de padrão construcional na voz passiva analítica com encobrimento parcial do referente-participante indutor (pesquisador/autor do texto acadêmico)

Ex. 11: Para tal, FORAM SELECIONADAS fibras têxteis, acrílicas, de vidro, de basalto, de banana e de sisal e estudou-se o efeito da sua incorporação em composições diferentes à base de gesso, procurando avaliar o seu comportamento, quer no estado fresco, quer no endurecido. [Revista de Engenharia Civil, 2013, No. 46, 5-17 I, p. 5]

(vi) constructo/uso de padrão construcional na voz passiva analítica com encobrimento parcial do referente-participante indutor (mediante sintagma preposicional com SN singular ou plural genérico/indefinido ${ }^{24}$ )

Ex. 12: "Sua peça teatral Hay amigo para amigo, foi publicada de forma anônima no ano de 1663 em Coimbra, não SENDO RECONHECIDA por muitos historiadores como seu primeiro trabalho" [Revista da Faculdade de Letras, História, Série IV, Vol. 07, Num. 2, 2017, p. 54 - nota de rodapé]

24 Considera-se a gradualidade envolvida no valor genérico ou indefinido relacionado ao atributo da referencialidade. 


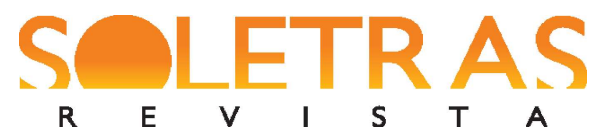

\section{N.37 - 2019.1 - MARCIA DOS SANTOS MACHADO VIEIRA JÚLIA LESSA DOS SANTOS \\ MORGANA PINHEIRO ALBUQUERQUE KROPF}

(vii) constructo/uso de padrão construcional na voz passiva analítica com encobrimento parcial do referente-participante indutor (circunstancializado em estrutura satélite/termo adjunto)

Ex. 13: "Sublinha-se que a descoberta da penicilina foi realizada à custa de: uma "intuição genial", um "acaso miraculoso", uma "descoberta prodigiosa", "prodígio", “milagre”, "acaso feliz", "lampejo de génio", etc.; atendendo às suas propriedades terapêuticas e aos seus benefícios para a Humanidade a penicilina FOI CLASSIFICADA jornalisticamente como "remédio maravilha", "remédio milagroso", "droga maravilhosa", "extraordinário remédio", etc. [Revista da Faculdade de Letras. História Série III, vol. 6, 2005 p. 147]

(vii) constructo/uso de padrão construcional na voz passiva analítica com encobrimento total do referente-participante indutor (não-identificável no texto)

Ex. 14: "No dia 15, O Primeiro de Janeiro continuava a noticiar o falecimento de Fleming dizendo que as suas cinzas SERIAM DEPOSITADAS na Catedral de São Paulo, em Londres, após a sua cremação (...)" [Revista da Faculdade de Letras. História Série III, vol. 6, 2005 pg. 146]

Desfocalização/desfocamento do papel participante indutor tem, aqui, uma concepção que cobre, então, diferentes graus, entre os quais se configuram, até o momento desta pesquisa, estas possibilidades: demoção/eversão (para uma posição sintática mais baixa, com a possibilidade de opacificação, indefinição ou imprecisão de identidade quando em segundo plano), supressão (default/suspensão ou não-preenchimento), circunstancialização.

\section{Material e tratamento da variação construcional aqui em jogo}

Em geral, espera-se o encobrimento de atores sociais no universo acadêmico da produção textual. A impessoalização/impersonalização discursiva é um fenômeno característico da linguagem científica, pode ser relacionada à busca de objetividade e de focalização do fazer científico e de desfocamento dos responsáveis por esse fazer e, ainda, a uma exigência do gênero discursivo (contexto discursivo). Vale lembrar que atua também 


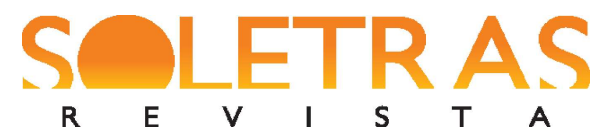

\section{N.37 - 2019.1 - MARCIA DOS SANTOS MACHADO VIEIRA JÚLIA LESSA DOS SANTOS \\ MORGANA PINHEIRO ALBUQUERQUE KROPF}

como um fenômeno de preservação de face (BROWN \& LEVINSON, 1987). Um dos subprojetos do Projeto PREDICAR diz respeito ao mapeamento da rede construcional de impessoalidade discursiva (cf., por exemplo, MACHADO VIEIRA, 2017). Com isso, importa detectar, na experiência dos usos linguísticos, todos os padrões construcionais que colaborem para isso.

Em estudos de línguas românicas (espanhola, italiana e francesa), há discussão sobre a relação entre impessoalidade e passividade. No espanhol, por exemplo, Suñer (2002, p. 211) argumenta que os padrões construcionais com SE impessoal propiciam a interpretação de um predicador como se aplicando a um conjunto não-específico de entidades no mundo biossocial, representado pelo SE. No italiano, Cinque (1988) examina o papel do SI impessoal, propondo variantes ligadas a seu uso como um sujeito genérico. Na língua francesa, Ruwet (1972) categoriza alguns tipos de orações sem agente como neutras. E, na língua portuguesa, Morais (2013) focaliza os usos do clítico SE em artigos acadêmicos sob o viés da Linguística Sistêmico-Funcional. Tais usos foram relacionados por esta autora à temática da impessoalização, típica da linguagem científica.

Interessa também a esta pesquisa estudar os padrões construcionais de predicação no Português Europeu (PE) acionados para a impessoalização discursiva de participante indutor na perspectivação de um estado de coisas. Para nossa primeira incursão na temática da variação na predicação verbal em voz passiva, analisaram-se 503 dados coletados em 41 artigos acadêmicos portugueses de revistas da área de humanas (história e linguística) e da área tecnológica (engenharia), localizadas em portais digitais de periódicos científicos de universidades portuguesas.

Pesquisaram-se condições ligadas a atributos implicados nos dados de uso aqui analisados que tivessem relação com as faces forma e função envolvidas nos pareamentos de passiva em análise. Então, procedeu-se a uma análise estatística preliminar, recorrendo-se ao programa Goldvarb X, dos 503 dados, com base nestas condições (vinculadas a atributos formais e funcionais):

- temática (área científica do artigo acadêmico);

- tempo (artigos produzidos em dois recortes temporais recentes);

- $\quad$ tipo de configuração da predicação/oração (desenvolvida ou reduzida);

- $\quad$ polaridade da predicação;

- tipo de construção de estrutura de argumentos; 


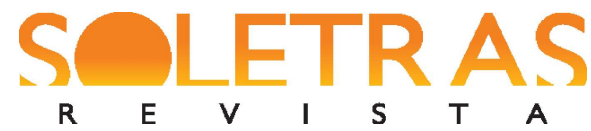

N.37 - 2019.1 - MARCIA DOS SANTOS MACHADO VIEIRA JÚLIA LESSA DOS SANTOS

MORGANA PINHEIRO ALBUQUERQUE KROPF

- $\quad$ tipo de estado de coisas (dinâmico com controle do participante indutor, dinâmico sem controle do participante indutor, não-dinâmico/avaliativo);

- natureza do participante indutor (participante 1) quanto a número e grau de especificidade (singular específico, singular genérico, plural específico, plural genérico, não-identificável);

- $\quad$ animacidade do participante 1 ;

- $\quad$ papel semântico do participante 1 ;

- grau de identificabilidade/estatuto informacional do participante 1 no contexto textual/discursivo (referente novo, referente evocado situacionalmente ou endoforicamente, referente inferível de outra parte do texto, referente não-identificável);

- natureza do participante afetado ou efetuado (participante 2) quanto a número e grau de especificidade;

- $\quad$ animacidade do participante 2 ;

- papel semântico do participante 2 (afetado/transformado, efetuado/feito, experimentado, locativo);

- presença ou ausência de adjunto circunstancial com "aparência" formal/semântica de constituinte argumento "agente da passiva"/oblíquo ou participante indutor de estado de coisas.

Quadro 1 - Variáveis (relacionadas a atributos formais e funcionais) consideradas no estudo de variação de padrões construcionais de predicação verbal na voz passiva no paradigma discursivo acadêmico em Portugal.

Controlou-se, num grupo de fatores específico, valores relativos à configuração de passivas analíticas (em que se observaram a morfossintaxe e a natureza da referencialidade na contextualização do participante indutor de estado de coisas).

Sobressaem, na análise estatística que se empreendeu até o momento, atributos de ordem semântica, discursiva, social: grau de identificabilidade/estatuto informacional do participante 1 no contexto textual/discursivo; temática/área do texto acadêmico; natureza do participante indutor (participante 1) quanto número e grau de especificidade; tipo de construção de estrutura de argumentos, papel semântico do participante 2. Na seção seguinte, sintetizam-se alguns dos resultados até então obtidos.

\section{Análise de dados de padrões construcionais de predicação verbal na voz passiva}

A pesquisa revela, em textos acadêmicos, dados em uso no Português de Portugal referentes a estes padrões construcionais de predicação verbal na voz passiva:

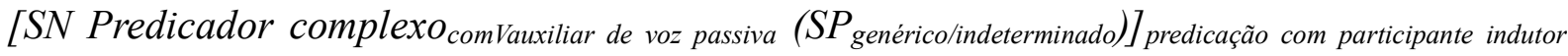
desfocalizadolfora de cena

Ex. 15: "Os povetesFORAM MANTIDOS em câmara húmida a uma temperatura de $21^{\circ} \mathrm{C}$; $2^{\circ} \mathrm{C}$ até SEREM ENSAIADOS". [Revista de Engenharia Civil , 2013, No. 46, 5-17 A; p. 8]

[Predicador-SESN] predicação com participante indutor desfocalizado/fora de cena 


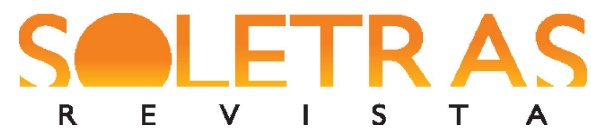

\section{N.37 - 2019.1 - MARCIA DOS SANTOS MACHADO VIEIRA JÚLIA LESSA DOS SANTOS \\ MORGANA PINHEIRO ALBUQUERQUE KROPF}

Ex. 16: "Durante o mesmo período, EFETUOU-SE o controlo da perda de massa das misturas, para além do registo da temperatura e da humidade ambiente." [Revista de Engenharia Civil, 2014, No. 49, 5-14 A; p. 7]

Postulou-se a hipótese de que o padrão construcional[Predicador-SESN]predicação com participante indutor desfocalizado/fora de cena é bastante usado na organização do discurso acadêmico português escrito. E se partiu da seguinte questão: qual é o estatuto dessa variação e o que afeta o acionamento mais frequente de um ou outro padrão?

Dos 503 dados, 371 são de passiva analítica $(73,8 \%)$ e 133 são de passiva sintética/pronominal (26,2\%). O input da variante construcional passiva pronominal fica em torno de .140 nos cálculos de influências das condições dos atributos examinados (.262, input inicial, sem considerar a coatuação de tais condições). Isso revelou maior inclinação ao acionamento do padrão construcional de passiva analítica no PE acadêmico ${ }^{25}$.

No estudo das condições estipuladas para captar atributos das faces forma e função desses padrões construcionais, detectam-se similaridades, uma vez que se encontram dados oriundos de ambos padrões construcionais em todos os contextos/fatores dos grupos examinados.

Ex. 17: UTILIZOU-SE um provete com 100x100x850 mm3 e a velocidade de propagação dos ultrassons por transmissão direta FOI REGISTADA durante 300 horas. [Revista de Engenharia Civil , 2014, No. 49, 5-14 A; p. 7]

Propriedades similares decorrentes de processos cognitivos - como (i) a desfocalização do participante indutor (via supressão, demoção para complemento verbal ou circunstancialização) e (ii) o direcionamento da atenção do interlocutor para o estado de coisas (científico) em si, para a avaliação de um estado de coisas em si ou para o participante afetado/efetuado no estado de coisas, com a retirada de cena ou de foco do participante indutor, - propiciam o alinhamento funcional (frequente) de dados resultantes desses dois padrões e, por conseguinte, a analogia desses padrões construcionais num espaço do

\footnotetext{
${ }^{25}$ Vale informar que, comparando-se subamostras de dados (dados oriundos de textos publicados antes de 2015 com dados de textos publicados depois de 2015), o percentual de sentenças na voz passiva analítica é maior na subamostra de publicações mais recentes: $84,1 \%$ dos 371 dados de passivas sintéticas - depois de 2015; 65,7\% dos 371 dados de passivas sintéticas - antes de 2015 .
} 


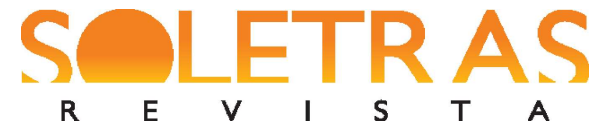

conhecimento linguístico em que a variabilidade por similaridade se instaura, a partir da habilidade geral para construir equivalências.

Embora por meio desta pesquisa se tenha registrado, empiricamente, variação relativa aos padrões construcionais de passiva sintética/pronominal e passiva analítica em relação a todos os aspectos das condições ligadas aos atributos de forma e função aqui considerados (sob um olhar socioconstrucionista), a investigação também revela inclinações diferentes (em termos de percentuais e probabilidades), a depender de certas condições, como se pode visualizar a seguir:

\begin{tabular}{|c|c|}
\hline Padrão de passiva sintética/pronominal (132 dados) & Padrão de passiva analítica (371 dados) \\
\hline $\begin{array}{l}\text { Participante indutor não-expresso (default) } \\
\text { (em } 26,02 \% \text { do corpus total/503 dados) }\end{array}$ & $\begin{array}{l}\text { Participante indutor não-expresso } \\
\text { (em } 57,73 \% \text { dos } 503 \text { dados, contra } 16,25 \% \text { de } \\
\text { expresso no corpus) }\end{array}$ \\
\hline $\begin{array}{c}\text { Participante indutor/referente evocado } \\
\text { situacionalmente (circunstancializado, em estruturas } \\
\text { satélites na predicação expandida ou no texto) }-80,9 \% \\
\text { das } 89 \text { sentenças com esse tipo de referente; com peso } \\
\text { relativo de } .880\end{array}$ & $\begin{array}{l}\text { Participante indutor/referente novo }(93,4 \% \text { das } 91 \\
\text { sentenças com esse tipo de referente) ou referente não- } \\
\text { identificável ( } 83 \% \text { das } 235 \text { sentenças com esse tipo de } \\
\text { referente) }\end{array}$ \\
\hline $\begin{array}{c}\text { Área tecnológica }(68,5 \% \text { em } 503 \text { dados }) \text { - com peso } \\
\text { relativo de } .770\end{array}$ & Área de humanas $(85,3 \%$ em 503 dados $)$ \\
\hline $\begin{array}{l}\text { Referente do participante indutor no singular } \\
\text { genérico/indefinido - com peso relativo de } .740\end{array}$ & $\begin{array}{l}\text { Referente do participante indutor no singular } \\
\text { específico/definido }\end{array}$ \\
\hline $\begin{array}{c}\text { Predicações nucleares a partir de predicadores verbais } \\
\text { envolvendo } 3 \text { papéis participantes (como, por } \\
\text { exemplo, sugerir, aconselhar, expor) - com peso } \\
\text { relativo de } .887\end{array}$ & $\begin{array}{c}\text { Predicações nucleares a partir de predicadores verbais } \\
\text { envolvendo } 2 \text { papéis participantes (como, por exemplo, } \\
\text { perceber, compreender }{ }^{26} \text { ) ou envolvendo } 2 \text { papéis } \\
\text { participantes e predicador nominal/“predicativo” do } \\
\text { segundo papel participante (avaliativos; como, por } \\
\text { exemplo, considerar/julgar }{ }^{27} \text { ) } \\
\text { e } \\
\text { Predicações nucleares a partir de predicadores verbais } \\
\text { envolvendo 3 papéis participantes (um deles de } \\
\text { natureza locativa; como, por exemplo, manter, } \\
\text { incluir }^{28} \text { ) }\end{array}$ \\
\hline
\end{tabular}

${ }^{26}$ Ex.: "Contudo, e apesar de frequentemente os agentes diplomáticos dominarem línguas estrangeiras, a presença de intérpretes não ERA DISPENSADA.” [PÉQUIGNOT, 2009: 217-221]. [Revista da Faculdade de Letras, História, Série IV, Vol. 07, Num. 2, 2017, p. 19]

${ }^{27}$ Ex.: "Cláudio Manuel da Costa, É IDENTIFICADO como um marco do movimento arcádico no Brasil, incorporando o regionalismo à cultura do Arcadismo." [Revista da Faculdade de Letras, História, Série IV, Vol. 07, Num. 2, 2017, p. 57]

${ }^{28}$ Ex.: "Em alguns casos, tal consoante intervocálica É mesmo MANTIDA ainda em algumas derivações morfológicas em português." [Revista de Estudos Linguísticos da Universidade do Porto, Vol. 12, 2017, p.219] 
MARCIA DOS SANTOS MACHADO VIEIRA JÚLIA LESSA DOS SANTOS

MORGANA PINHEIRO ALBUQUERQUE KROPF

\begin{tabular}{|c|c|}
\hline $\begin{array}{c}\text { Estado de coisas dinâmico sem o controle do } \\
\text { participante indutor }{ }^{29-46,3 \% \text { das } 28 \text { sentenças desse tipo; com peso }} \\
\text { relativo de } .899\end{array}$ & $\begin{array}{l}\text { Estado de coisas não-dinâmicos/avaliativos } \\
149 \text { sentenças desse tipo }\end{array}$ \\
\hline Papel participante efetuado/feito ${ }_{\text {tipo }}^{-30,6 \% \text { das } 124 \text { sentenças desse }}$ & $\begin{array}{l}\text { Papel participante experimentado (psicologicamente, } \\
\text { emocionalmente, fisicamente) }-82,4 \% \text { das } 51 \text { sentenças desse tipo }\end{array}$ \\
\hline
\end{tabular}

Quadro 2 - Distribuição percentual dos dados segundo condições/propriedades implicadas na configuração oracional por recurso aos padrões construcionais em variação na predicação verbal na voz passiva. ${ }^{31}$

Consoante se observa nesse quadro, diferentes modos de percepção/representação de um estado de coisas podem determinar a mobilização preferencial de um ou outro padrão construcional para a configuração da predicação verbal na voz passiva, a depender de certas condições. Até o momento, o que se evidencia, a partir do tratamento estatístico dos dados, é a hipótese de que tais condições não atuam como contextos de restrição ao acionamento de um ou outro padrão. Antes atuam como um conjunto de condições às quais se alinham mais ou menos frequentemente dados de um outro padrão, sem impedir o acionamento de qualquer um deles. Com isso, fortalece-se a concepção de partida de que há uma área de generalização comum/alinhamento funcional em que se relacionam padrões construcionais de passiva sintética e analítica independentes (nós na rede construcional): área chamada na literatura de metaconstrução. Esta não se confunde com um nível hierarquicamente mais esquemático, uma vez que captura não só semelhanças/similaridades sistemáticas como também diferenças/dissimilaridade entre eles (muitas vezes, sutis ou difíceis de notar) e, em decorrência de uma perspectivação que, sistematicamente, dá centralidade aos atributos partilhados por eles, os conecta, tendo por base o processo cognitivo da analogia e a habilidade humana para estabelecer equivalências.

\footnotetext{
${ }^{29}$ Ex.: "Através da tabela é possível verificar que a quantidade de água necessária para SE OBTER argamassas com a mesma trabalhabilidade é reduzida com a crescente incorporação de finos de loiça sanitária." [Revista de Engenharia Civil, 2016, No.53, 57-69A; p. 11]

30 Estados de coisas dinâmicos com controle do participante indutor são expressos por ambos padrões construcionais, embora haja mais dados de sua manifestação no corpus viabilizada mediante o subesquema construcional de passiva analítica $(81,8 \%$ dos 325 dados com essa configuração de estados de coisas, contra $18,2 \%$ dos mesmos 325 dados em passiva sintética/pronominal).

31 Os pesos relativos foram calculados para dados de passiva sintética (valor de aplicação na rodada multivariada). Pesos acima de .500 são índices que sinalizam condições propícias ao acionamento de uma das variantes em jogo. Pesos próximos a .500 revelam neutralidade. E pesos abaixo de .500 indicam baixa interferência do atributo em questão.
} 


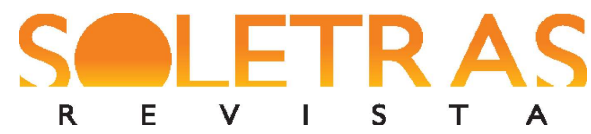

N.37 - 2019.1 - MARCIA DOS SANTOS MACHADO VIEIRA
JÚLIA LESSA DOS SANTOS
MORGANA PINHEIRO ALBUQUERQUE KROPF

A variante morfossintática do padrão construcional de predicação na voz passiva com pronome apassivador leva, em tese, à inviabilização da manifestação do papel participante indutor na estruturação do estado de coisas em termos de predicação nuclear (ou seja, predicação que envolve papéis participantes nucleares à configuração do estado de coisas projetado pelo predicador). Ocorre que, na predicação expandida por constituintes adjuntos, o participante indutor pode ser, em alguma medida, acessado na oração e/ou no período/texto (conforme se nota no primeiro exemplo a seguir). Também pode ser captado por conta do próprio gênero textual que remete o leitor ao pesquisador/autor do texto acadêmico (conforme os dois outros exemplos abaixo).

Ex.18: "O jornal Novidades noticiava com o seguinte título: "Fleming o inventor da penicilina morreu ontem em Londres"; na notícia SUBLINHA-SE o valor da descoberta de Fleming e FAZ-SE um esboço biográfico do cientista, muito semelhante a outros publicados no país ou no estrangeiro. [Revista da Faculdade de Letras, História, Série III, vol. 6, 2005 p. 147]

Ex. 19: “(...) para a análise não-linear UTILIZARAM-SE vários tipos de elementos finitos, em função das não-linearidades geométricas tidas em conta: para a avaliação isolada do efeito P- $\Delta$ foram utilizados o elemento de biela e o elemento de viga de formulação geometricamente não-linear (...)" [Revista de Engenharia Civil, 2006, No. 25, 61-72 A; p. 62]

Ex. 20: Assim, de modo a ESTUDAR-SE o desempenho estrutural dos pavimentos rodoviários ANALISOU-SE um vasto conjunto de secções representativas da rede rodoviária nacional, sendo a estrutura, a zona climática e o tráfego os principais critérios de selecção.” [Revista de Engenharia Civil, 2001, No. 11, 47-58 I; p. 48]

\section{Destaques finais}

Com esta breve incursão em prol da inclusão da variação entre as generalizações mapeadas na arquitetura da Linguística Funcional-Cognitiva, objetivou-se reunir subsídios (advindos de leituras ou análises empíricas empreendidas no Projeto PREDICAR - Formação e expressão de predicados complexos) e, daí, começar a responder a questionamentos feitos 


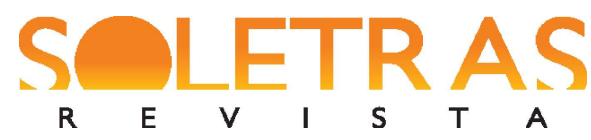

\section{N.37 - 2019.1 - MARCIA DOS SANTOS MACHADO VIEIRA JÚLIA LESSA DOS SANTOS \\ MORGANA PINHEIRO ALBUQUERQUE KROPF}

quando se põe em discussão a temática da representação da diversidade linguística nesse modelo.

Nesta oportunidade, escolheu-se abordar a relação de similaridade entre padrões construcionais detectada em análises (no referido projeto) de dados do comportamento linguístico ou de resultados de testes de percepção ou avaliação subjetiva sobre estes dados. E, por consequência, esboçaram-se observações sobre contribuições, desafios, implicações, possibilidades e ajustes envolvidos nessa empreitada. Explorou-se, mais especificamente, o espaço da predicação verbal por meio do qual se busca encobrir total ou parcialmente um papel participante previsto pelo predicador (a força indutora do estado de coisas), um papel argumental da estrutura de argumentos (agente, experienciador, dizente, portador). Não se pretendeu dar conta, no âmbito deste artigo, da totalidade de implicações dos aspectos aqui tratados, mas, antes, sinalizar alguns "ingredientes" num cenário de práticas de pesquisa construcionista nem sempre favorável à proposição de um lugar para a variação, embora essa proposição já conte com alguma acolhida (de HOFFMANN \& TROUSDALE, 2011 ou de KAVAN, 2012, dentre outros aqui citados).

\section{Referências}

BOYD, J. K. \& GOLDBERG, A. E. Learning what not to say: the role of statistical preemption and categorization in A-adjective production. Language, v. 87, n. 1, 2011.

BROWN, P. \& LEVINSON, S. C.Politeness. Some Universals in Language Usage.Cambridge: Cambridge University Press, 1987.

CAPPELlE, B. Particle placement and the case for "allostructions". Constructions, Special, v. 1, p. $1-28,2006$.

. Can we factor out free choice? In: DUFTER, A., FLEISCHER, J. \& SEILER, G. Describing and Modeling Variation in Grammar. Berlin/New York: Mouton de Gruyter. p. 183-199, 2009.

CINQUE, G. On si constructions and the theory of Arb. Linguistics Inquiry, v. 19, n. 4, p. 521-581, 1988.

ECKERT, P. Three waves of Variation Study: the emergency of meaning in the study of Variation. Annual Review of Anthropology, v. 41, 2012. p. 87-100. 


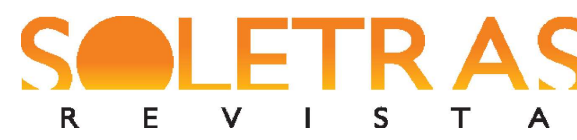

N.37 - 2019.1 - MARCIA DOS SANTOS MACHADO VIEIRA JÚLIA LESSA DOS SANTOS

MORGANA PINHEIRO ALBUQUERQUE KROPF

GOLDBERG, A. E. Constructions: a construction grammar approach to argument structure. Chicago: The University of Chicago Press, 1995.

Constructions: A new theoretical approach to language. Trends in Cognitive Sciences, 7, p. 219-224, 2003.

Compositionality. In: RIEMER, N. (ed.) The Routledge Handbook of Semantics. New York: Routledge, 2016. p. 419-430.

HILPERT, M. Construction Grammar and its Application to English. Edinburgh: Edinburgh University Press, 2014.

HUNDT, M.; RÖTHLISBERGER, M; SEONE, E. Predicting voice alternation across academic Englishes. In: WULFF, S. (ed.) Corpus Linguistics and Linguistic Theory, 2018 (aop).(periodic fundado por GRIES, S. Th.; STEFANOWITSCH, A.)

HOFFMANN, T.; TROUSDALE, G. Variation, change and constructions in English. Cognitive Linguistics. v. 22, n. 1, p. 1-23, 2011.

KAVAN, J. Evidence in linguistics: corpus-linguistic and experimental methods for studying grammatical synonymy. Doctoral dissertation. University of Tartu, Institute of Estonian and General Linguistics: University of Tartu Press, 2012. 286 fl.

LABOV, W. Sociolinguistic patterns. Philadelphia, PA: University of Pennsylvania Press, 1972.

LEINO, L.; ÖSTMAN, J-O. Constructions and variability. In.: FRIED, M.; BOAS. H. C. Grammatical Constructions: back to the roots. Amsterdam/Philadelphia: John Benjamins Publishing Company. p. 192-213, 2005 (Constructional Approaches to Language).

MACHADO VIEIRA, M. S. Expressões impessoais no discurso acadêmico brasileiro. Revista Letrônica, v. 10, n. 1, 2017.

. Variação e mudança na descrição construcional: complexo verbo-nominais. Revista Linguística, v. especial, p. 152-170, 2016. Disponível em: $<$ https://revistas.ufrj.br/index.php/rl/article/view/5445/4037>.

- Panorama da norma de flexão verbal de número em construções com SE apassivador/indeterminador. Cuadernos de LA ALFAL, 7, marzo, p. 152-170, 2015. $<$ http://www.mundoalfal.org/sites/default/files/revista/07_cuaderno_013.pdf >.

MORAIS, F. B. C. de. Entre alhos e bugalhos: os usos do clítico SE na escrita acadêmica. Tese (Doutorado em Linguística Aplicada e Estudos da Linguagem). São Paulo, Pontifícia Universidade Católica, 2013. 


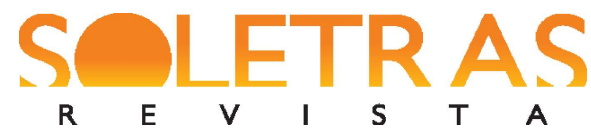

N.37 - 2019.1 - MARCIA DOS SANTOS MACHADO VIEIRA
JÚLIA LESSA DOS SANTOS
MORGANA PINHEIRO ALBUQUERQUE KROPF

PEREK, F. The status of alternations in construction grammar: a sorting task experiment, 2012. Disponível em: <http://www.fperek.net/pdfs/abstract_AFLiCoIV.pdf $>$.

Argument Structure in Usage-Based Construction Grammar: experimental and corpus-based perspectives. Amsterdam/Philadelphia: John Benjamins Publishing Company, 2015.

PEREIRA, B. C. A. A expressão do aspecto de fases no Português: um novo olhar centrado em construções perifrásticas. Dissertação de Mestrado (Letras Vernáculas). Rio de Janeiro, Universidade Federal do Rio de Janeiro, 2016.

RUWET, N. Théorie syntaxique et syntaxe Du français.Paris: Seuil, 1972.

SHIBATANI, M. Passives and related constructions: a prototype analysis. Language. v. 61, n. 4, p. 821-848, 1985.

SUÑER, M. Las pasivas con se impersonal y la legitimación de las categorias vacías. In: LOPES, C. S. Las construciones com se. Madri: Visor Libros, 2002.

TAVARES, Ma. A. \& GORSKI, E. M. Variação e sociofuncionalismo. In: MARTINS, M. A., ABRAÇADO, J. (orgs.) Mapeamento sociolinguístico do Português brasileiro. São Paulo: Contexto, 2015.

TRAUGOTT, E. C.; TROUSDALE, G. Constructionalization and Constructional Changes. Oxford: Oxford, 2013.

\title{
Constructional variation by analogy: constructional patterns of verbalpredication in the passive voice
}

\begin{abstract}
This article deals with the theme of the space of the variation between the generalizations of the Construction Grammar and about an analysis, under a socioconstructionist point of view, of constructional patterns of verbal predication in the passive voice. It aims to present arguments for the study of linguistic variation by similarity and to illustrate variation of constructional patterns of (pronominal and analytical) passive verbal predication. It is based on the assumptions of FunctionalCognitive Linguistics, which focuses on linguistic experience. In general terms, it collaborates to the reflection about the potential of functional alignment of independent constructional subschemas and microconstructions that it maps, based on methodology of statistical treatment and on description of data of sentences in the synthetic and analytic passive voice. It reveals three configuration possibilities of verbal predication from the constructional subschema of pronominal passive and four configuration possibilities verbal predication from the constructional subschema of analytical passive.
\end{abstract}




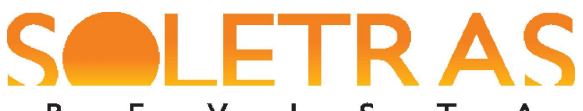

$\begin{array}{llllllll}\mathbf{R} & \mathbf{E} & \mathbf{V} & \mathbf{I} & \mathbf{S} & \mathbf{T} & \mathbf{A} & \mathrm{N} .37-2019.1-\text { MARCIA DOS SANTOS MACHADO VIEIRA }\end{array}$

JULIA LESSA DOS SANTOS

MORGANA PINHEIRO ALBUQUERQUE KROPF

Keywords: Constructional variation; Verbal predication; Passive.

Recebido em: 26 de novembro de 2018.

Aceito em: 29 de março de 2019. 